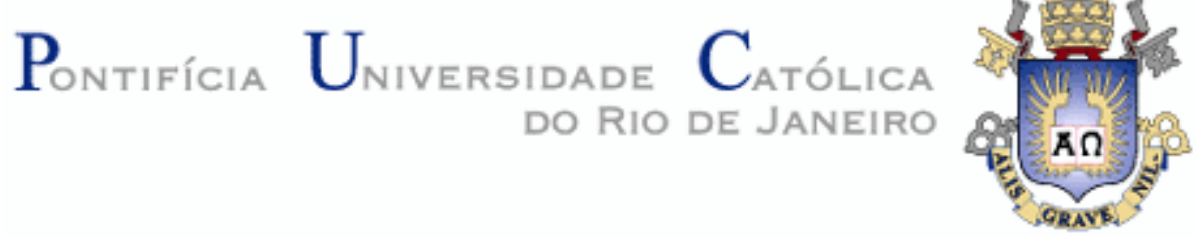

Fábio Facchinetti Freire

\title{
"Estamos alunos": um estudo sobre a identidade contemporânea dos alunos do Colégio Militar do Rio de Janeiro
}

Tese de Doutorado

Orientadora: Prof. ${ }^{\text {a }}$ Maria Isabel Mendes de Almeida

Tese apresentada como requisito parcial para obtenção de grau de doutor pelo Programa de Pós-Graduação em Ciências Sociais da Pontifícia Universidade Católica do Rio de Janeiro.

Volume I 


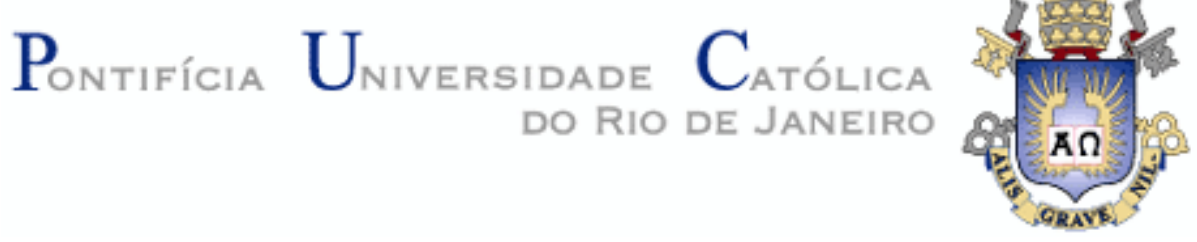

Fábio Facchinetti Freire

\section{"Estamos alunos": um estudo sobre a identidade contemporânea dos alunos do Colégio Militar do Rio de Janeiro}

Tese apresentada como requisito parcial para obtenção do grau de Doutor pelo Programa de PósGraduação em Ciências Sociais do Departamento de Ciências Sociais do Centro de Ciências Sociais da PUC-Rio. Aprovada pela Comissão Examinadora abaixo assinada.

Profa. Maria Isabel Mendes de Almeida
Orientadora
Departamento de Ciências Sociais/PUC-Rio

Profa. leda Tucherman

UFRJ

Profa. Mylene Mizrahi

UFRJ

Prof. Valter Sinder

Departamento de Ciências Sociais/PUC-Rio

Profa. Sônia Maria Giacomini

Departamento de Ciências Sociais/PUC-Rio

Profa. Mônica Herz

Coordenadora Setorial do Centro de Ciências Sociais - PUC-Rio

Rio de Janeiro, 21 de agosto de 2015 
Todos os direitos reservados. É proibida a reprodução total ou parcial do trabalho sem autorização da universidade, do autor e do orientador.

\section{Fábio Facchinetti Freire}

"Graduou-se em Ciências Militares pela Academia Militar das Agulhas Negras (1988). Possui mestrado em Ciências Militares pela Escola de Aperfeiçoamento de Oficiais (1996) e Mestrado em Educação pela Universidade Federal do Estado do Rio de Janeiro (2007). Chefia a Seção de Ensino do Sistema Colégio Militar do Brasil desde 2008. Tem interesse em Ciências Sociais e Educação".

Freire, Fábio Facchinetti

"Estamos alunos": um estudo sobre a identidade contemporânea dos alunos do Colégio Militar do Rio de Janeiro / Fábio Facchinetti Freire ; orientadora: Maria Isabel Mendes de Almeida. - 2015. 357 f. 2v: il. (color.) ; $30 \mathrm{~cm}$

Tese (doutorado)-Pontifícia Universidade Católica do Rio de Janeiro, Departamento de Ciências Sociais, 2015.

Inclui bibliografia

1. Ciências Sociais - Teses. 2. Teoria do Ator-Rede. 3. Sociologia dos militares. 4. Contemporaneidade. I. Almeida, Maria Isabel Mendes de. II. Pontifícia Universidade Católica do Rio de Janeiro. Departamento de Ciências Sociais. III. Título.

CDD: 300 


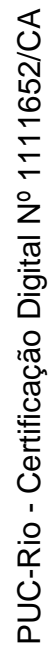

Ao meu filho João Pedro: que ele não precise de heróis. 


\section{Agradecimentos}

Aos meus pais, por sua crença injustificada em mim.

À minha esposa Aleciane, sempre presente em minhas ausências.

Ao Comando do CMRJ, por me franquear as portas da Casa de Thomaz Coelho.

Aos alunos do grupo "Nicodemus Contemporâneo", em especial à Aluna Úrsula Passos, como mediadores privilegiados de meus olhares sobre o CMRJ.

À psicóloga Hilda, do CMRJ, por seus infinitos toques e contatos.

Aos membros da Seção de Ensino da DEPA, meus Edukators, por segurarem a barra de minha ausência e por compartilharem do mesmo amor ao SCMB.

À minha orientadora, Prof ${ }^{a}$ Maria Isabel Mendes de Almeida, pela onipresença elegante de sua orientação. Nunca ninguém foi tão orientado, sem se sentir conduzido.

Às professoras Mylene Mizhari e Sonia Maria Giacomini, que me qualificaram e aceitaram retornar ao meu trabalho, como membros da banca, na defesa da tese.

Aos professores Yeda Tucherman e Valter Sinder que também abrilhantaram minha defesa com experiência inigualável.

À equipe da secretaria da pós, solícita como não encontrei em outras instituições nas quais estudei, com destaque para a liderança da Ana Roxo - militares reparam muito em lideranças... 


\section{Resumo}

Freire, Fábio Facchinetti; Almeida, Maria Isabel Mendes de. "Estamos alunos": um estudo sobre a identidade contemporânea dos alunos do Colégio Militar do Rio de Janeiro. Rio de Janeiro, 2015. 357p. Tese de Doutorado. Departamento de Ciências Sociais. Pontifícia Universidade Católica do Rio de Janeiro.

Esta investigação objetivou conhecer o aluno contemporâneo do Colégio Militar do Rio de Janeiro (CMRJ), em sua relação com as fardas, as insígnias, a linguagem e os gestos privativos do Exército Brasileiro, considerando que a Força Armada lança mão destes itens identitários para a reprodução de seu espírito militar. A pesquisa utilizou, como metodologia, a Teoria do Ator-Rede (ActorNetwork Theory), de Latour, bem como o conceito de dispositivo, a partir de Foucault e ampliado por Agamben. Na estratégia de "seguir os atores" foram identificadas as apropriações, releituras e ressignificações por meio das quais os discentes convivem no CMRJ e, também, de que maneira a própria instituição militar colabora para com esse processo.

\section{Palavras-chave}

Teoria do Ator-Rede, sociologia dos militares, contemporaneidade. 


\section{Abstract}

Freire, Fábio Facchinetti; Almeida, Maria Isabel Mendes de. (Advisor) "We are students": a study on the contemporary identify of students of Colégio Militar do Rio de Janeiro. Rio de Janeiro, 2015. 357p. PhD's Thesis. Department of Social Sciences. Pontifícia Universidade Católica do Rio de Janeiro.

The objective herein was to get acquainted with the contemporary students of Colégio Militar do Rio de Janeiro (CMRJ), in their relation with the uniforms, the insignia, the language and the private gestures of the Brazilian Army, considering that the respective Armed Force makes use of these identity items to reproduce its military spirit. The research methodology used was the ActorNetwork Theory (ANT), by Latour, and we also worked with Foucault's notion of device ("dispositif"), revisited by Agamben. On the strategy of "following the actors", the adjustments, the reinterpretations and the resignifications were identified by means of what the students share at school, in the same way it was observed the way the military institution itself contributes to this process.

\section{Keywords}

Actor-Network Theory, sociology of military, contemporaneity. 


\section{Sumário}

$\begin{array}{ll}\text { Introdução } & 18\end{array}$

1. Fundamentação teórica 30

1.1. O que é o contemporâneo? 30

1.2. Para uma sociologia das associações 35

1.3. A Teoria do Ator-Rede 41

1.4. Os dispositivos $\quad 47$

2. Historiando os Colégios Militares 57

2.1. Introdução 57

2.2. Antecedentes: como nascer de acordo com as conveniências $\quad 59$

2.3. A origem do Colégio Militar do Rio de Janeiro 66

2.4. O Exército do Marechal José Pessoa 72

2.5. Os Colégios Militares no século XX 77

2.6. Pequeno esboço sobre uma pedagogia patronímica 81

3. Dimensionando os Colégios Militares 92

3.1. O Sistema Colégio Militar do Brasil como um todo 92

3.2. E o Colégio Militar do Rio de Janeiro, em particular 107

$\begin{array}{ll}\text { Interlúdio } & 119\end{array}$

4. Pode vestir a farda: etnografia da entrada dos novos alunos 131

4.1. introdução 131

4.2. O lugar como história: topografia com a contribuição de
Berque

4.3. Descrevendo o CMRJ 140

4.4. A cerimônia de entrada dos novos alunos 149

4.5. A entrega da boina garança 159

4.6. Conclusões 170

5. "Ao chorarmos a saudade do Colégio Militar": etnografia da cerimônia de aniversário do CMRJ 173

5.1. Introdução 173

5.2. O "seis de maio" de 2014

5.3. Conclusões 203

6. Estamos alunos 209

6.1. Notas sobre a metodologia $\quad 209$

6.2. As manhãs no CMRJ 215

6.3. O processo de encantamento e de desencantamento 234

6.4. A escolha das Armas 243

6.5. Tipologia dos alunos em relação à tipologia das Armas $\quad 259$

6.6. O peso dos símbolos 266

6.7. Os usos reinventados dos uniformes 282

6.7.1. De perto, ninguém é normal 282

6.7.2. Os cabelos 283 
6.7.3. As boinas 294

6.7.4. Os brincos e os piercings $\quad 300$

6.7.5. Os culotes 308

6.7.6. "Quero estar bonita porque sei que serei vista" 315

6.8. Descompromisso e sazonalidade 322

6.9. As resistências ativas e passivas 327

6.10. O banho de piscina 331

$\begin{array}{ll}\text { Conclusão } & 336\end{array}$

$\begin{array}{ll}\text { Referências bibliográficas } & 351\end{array}$ 


\section{Lista de figuras}

Figura 1: Prédio da Companhia de Infantaria (Cialnf) 115

Figura 2: Prédio da Companhia de Comunicações (CiaCom) 116

Figura 3: Prédio da Bateria de Artilharia (BiaArt) 116

Figura 4: Picadeiro do CMRJ, parte das instalações do Esquadrão de Cavalaria (EsqdCav)

Figura 5: Juramento à Bandeira Nacional, 25 de agosto de 2014

Figura 6: Portão principal, nos dias de hoje $\quad 140$

Figura 7: Portão principal, em 1911

Figura 8: Muro frontal do Colégio $\quad 141$

Figura 9: Começo da Alameda Dom Pedro II 143

Figura 10: Placa com menção ao Sgt Max Wolff Filho 144

Figura 11: Ponto médio da Avenida, onde foi estendida a faixa 145

Figura 12: Placa contendo exortação aos valores cultuados no Colégio 145

Figura 13: Outdoor fixado no Pavilhão Ribeiro Guimarães 146

Figura 14: Fim da Avenida; vislumbre da Praça Thomaz Coelho 146

Figura 15: Mastro da Bandeira Nacional $\quad 147$

Figura 16: Palacete da Babilônia, ou Casa Rosa 147

Figura 17: "Portão Monumental" da Academia Militar das Agulhas Negras 149

Figura 18: Entrada dos novos cadetes $\quad 150$

Figura 19: Novos alunos em forma para a entrada cerimonial 151

Figura 20: Movimento de sair pelo portão da direita e entrar pelo da esquerda 154

Figura 21: Vista da Rua General Canabarro 158

Figura 22: "Apresentação da(s) tropa(s)", pelos militar e aluno mais antigos 160

Figura 23: Hasteamento da Bandeira Nacional 161

Figura 24: Entrega da boina garança 163

Figura 25: Passagem da mascote Nicodemus 166

Figura 26: Desfile da Infantaria 167

Figura 27: Desfile da Cavalaria $\quad 167$

Figura 28: Uniforme $3^{\circ}$ B CM, segundo o Regulamento de Uniformes do Exército (RUE)

Figura 29: Uniforme 3ㅇ A CM 169

Figura 30: Maior autoridade chegando ao CMRJ 177

Figura 31: Gen Montezano passando em revista a Guarda de Honra 178 
Figura 32: Premiação da Aluna $1^{\underline{a}}$ colocada no $9^{\circ}$ ano do Ensino Fundamental

Figura 33: Alunas na posição inicial para a colocação da corbélia 182

Figura 34: Alunas carregando a corbélia para os homenageadores $\quad 183$

Figura 35: Alunas colocam a corbélia $\quad 183$

Figura 36: Alunas reverenciam o Patrono, junto com os homenageadores 183

Figura 37: Vista frontal do túmulo 184

Figura 38: Bloco que sustenta a placa com o juramento do aluno 185

Figura 39: Juramento do aluno $\quad 185$

Figura 40: Juramento do ex-aluno 186

Figura 41: Estátua do aluno fardado que guarda o túmulo 186

Figura 42: Início do desfile $\quad 192$

Figura 43: Detalhe da aproximação da Banda do CMRJ 192

Figura 44: Início do desfile, com a turma mais antiga participante 193

Figura 45: Passagem das turmas de 1960 - 69

Figura 46: Contorno, em sentido horário, da Praça Thomaz Coelho 194

Figura 47: O ex-aluno Castrinho puxando o "zum zaravalho" 195

Figura 48: Desfile de turmas contendo militares ainda na ativa 195

Figura 49: Começo do desfile com mulheres 196

Figura 50: Aumenta a presença das boinas 196

Figura 51: Turma de 2013, a última formada 197

Figura 52: Início do desfile do CMRJ: mascote "Nicodemus" 197

Figura 53: Desfile da Guarda de Honra 198

Figura 54: Desfile masculino da Infantaria, com coturnos 198

Figura 55: Desfile feminino da Infantaria, sem coturnos 199

Figura 56: Desfile único da Cavalaria, com seu mascote privativo 199

Figura 57: Desfile da Artilharia, em um único bloco 200

Figura 58: O desfile das Comunicações, com seus equipamentos e flâmulas 200

Figura 59: Desfile da 4⿳亠丷厂 $\mathrm{Cia}, 9^{\circ}$ ano do Ensino Fundamental 201

Figura 60: Desfile das meninas do 6ํano 201

Figura 61: Aluno comandante do desfile hipomóvel saúda a maior autoridade 202

Figura 62: Demais alunos no desfile hipomóvel 202

Figura 63: Divisa de aluno do 3ํㅡ EM 237

Figura 64: Insígnias de oficiais-alunos 238

Figura 65: Insígnias de praças-alunos $\quad 238$ 
Figura 66: Aluno portando o alamar 239

Figura 67: Brasão da Legião de Honra 240

Figura 68: Momento do juramento dos novos legionários 241

Figura 69: Alunos de Comunicações durante a formatura, ocupando o centro do espaço 253

Figura 70: Foto comemorativa, após a formatura 253

Figura 71: Destaque para os alunos com complementos em vermelho e branco

254

Figura 72: Desfile iniciado pelos alunos homenageados 254

Figura 73: Entrada dos alunos $\quad 255$

Figura 74: "Pagação" dos alunos 255

Figura 75: Entrada dos alunos $\quad 255$

Figura 76: Foto de todos os alunos, com a bandeira ao fundo 256

Figura 77: Momento da "pichação" em azul 257

Figura 78: Calouros pintados, cantoria 257

Figura 79: Calouros pintados, com o tobogã ao fundo 258

Figura 80: Calouro sendo molhado durante o percurso de rastejo 258

Figura 81: Fidelidade ao uso dos símbolos 266

Figura 82: "Classificação propedêutica" 280

Figura 83: Corte de cabelo, em vista frontal e lateral 284

Figura 84: Corte de cabelo, vista traseira 284

Figura 85: Corte feminino curto 285

Figura 86: Corte feminino, rabo-de-cavalo 285

Figura 87: Corte feminino, coque 286

Figura 88: Corte de cabelo masculino no CMRJ 286

Figura 89: Corte de cabelo feminino, rabo-de-cavalo 287

Figura 90: Corte de cabelo feminino, coque 287

Figura 91: Corte de cabelo feminino, curto 287

Figura 92: Al Sabrina, rabo-de-cavalo longo (mecha roxa) 289

Figura 93: Al Sabrina, rabo-de-cavalo longo (mecha vermelha) 289

Figura 94: Al Sabrina, rabo-de-cavalo longo (mecha verde) 290

Figura 95: Al Luna, 2 EM/Inf 292

Figura 96: Aluna não identificada, com o corte "undercut" 293

Figura 97: Exemplo de como usar, ํㅜ 1

Figura 98: Exemplo de como usar, ํo 2

Figura 99: Exemplo de como usar, ํㅡ 3

Figura 100: Exemplo de como usar, ํo 4 
Figura 101: À esquerda, uma boina francesa; à direita, uma boina nacional 297

Figura 102: Exemplo de boinas seguindo o uso regulado 297

Figura 103: A boina da direita é uma "pizza"; ao fundo, várias outras "pizzas"

298

Figura 104: A boina da esquerda é uma "pizza com topete" 298

Figura 105: Outro exemplo de "pizza com topete" 299

Figura 106: Exemplo dos três tipos: regular, "pizza" e "pizza com topete" 300

Figura 107: Piercings do cepto, do tragus e alargador 303

Figura 108: Outra vista do piercing do tragus e do alargador 303

Figura 109: Piercing na cartilagem interna do ouvido 304

Figura 110: Piercing no "smile" virado para baixo (aparecendo) 305

Figura 111: Detalhe da posição do piercing no "smile" 305

Figura 112: Piercing no "smile" escondido 306

Figura 113: Piercing "surface tragus" aparecendo 306

Figura 114: Piercing "surface tragus" escondido 307

Figura 115: Piercing na nuca aparecendo 307

Figura 116: Piercing na nuca escondido 308

Figura 117: Uniforme 3ำ D3, segundo o RUE 309

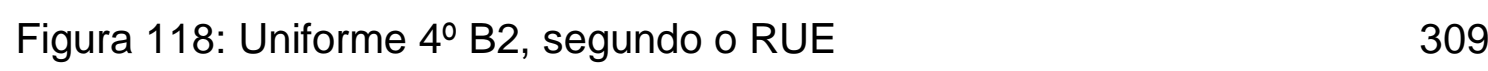

Figura 119: Uniforme 3 A CM, segundo o RUE 310

Figura 120: Uniforme 5ㅇ B3 CM, segundo o Manual do Aluno 2015

Figura 121: Uniforme 3을 CM, segundo o Manual do Aluno 2015

Figura 122: Uso do culote apertado, fora da situação de montaria, em 2004

Figura 123: Uso do culote apertado, fora da situação de montaria, em 2008

Figura 124: Uso do culote apertado, fora da situação de montaria, em 2014

314

Figura 125: Uso da calça apertada, por alunas da Arma de Infantaria, em 2015

Figura 126: Desfile de 7 de setembro 318

Figura 127: Pulo na piscina, 2014 - momento I 331

Figura 128: Pulo na piscina, 2014 - momento II 332

Figura 129: Pulo na piscina, 2014 - momento III 334

Figura 130: Pulo na piscina, 2014 - momento IV 334

Figura 131: Pulo na piscina, 2014 - momento V 335 


\section{Lista de siglas e abreviaturas}

1BG - 1ํㅡㄹ Batalhão de Guardas

$31^{\circ}$ GAC/Es - 31 Grupo de Artilharia de Costa - Escola

ACM - Atividade Cívico-Militar

AE - Avaliação de Estudo

AFA - Academia da Força Aérea

Al - Aluno

ALERJ - Assembleia Legislativa do Rio de Janeiro

AMAN - Academia Militar das Agulhas Negras

ANT - (Actor-Network Theory) Teoria do Ator-Rede

Art/CMRJ - Artilharia do Colégio Militar do Rio de Janeiro

AtvEst - Atividade de Estudo

Bia Art - Bateria de Artilharia

C 22-5 - Regulamento da Ordem Unida

Cav/CMRJ - Cavalaria do Colégio Militar do Rio de Janeiro

CCSv - Companhia de Comando e Serviços

CEFET/RJ - Centro Federal de Educação Tecnológica Celso Suckow da Fonseca

Cia Al - Companhia de Alunos

Cia Com - Companhia de Comunicações

Cia Inf - Companhia de Infantaria

$\mathrm{CM}$ - Colégio Militar

CMB - Colégio Militar de Brasília

$\mathrm{CMBH}$ - Colégio Militar de Belo Horizonte

CMC - Colégio Militar de Curitiba

CMCG - Colégio Militar de Campo Grande

CMF - Colégio Militar de Fortaleza

CMJF - Colégio Militar de Juiz de Fora

CMM - Colégio Militar de Manaus

CMPA - Colégio Militar de Porto Alegre

CMR - Colégio Militar do Recife

CMRJ - Colégio Militar do Rio de Janeiro

CMS - Colégio Militar de Salvador

CMSM - Colégio Militar de Santa Maria 
Cmt - Comandante

CNE - Conselho Nacional de Educação

Com/CMRJ - Comunicações do Colégio Militar do Rio de Janeiro

DECEx - Departamento de Educação e Cultura do Exército

DEPA - Diretoria de Ensino Preparatório e Assistencial (1973 - 2011)

DEPA - Diretoria de Educação Preparatória e Assistencial $(2011$ - ... $)$

E-1 - Estatuto dos Militares

EB - Exército Brasileiro

ECEME - Escola de Comando e Estado-Maior do Exército

EF - Ensino Fundamental

EFOMM - Escola de Formação de Oficiais da Marinha Mercante

EM - Ensino Médio

EM/Art - Ensino Médio de Artilharia

EM/Cav - Ensino Médio de Cavalaria

EM/Com - Ensino Médio de Comunicações

$E M / I n f$ - Ensino Médio de Infantaria

ENEM - Exame Nacional do Ensino Médio

EPCAr - Escola Preparatória de Cadetes do Ar

EsFCEx - Escola de Formação Complementar do Exército

ESG - Escola Superior de Guerra

EsPCEx - Escola Preparatória de Cadetes do Exército

Esqd Cav - Esquadrão de Cavalaria

EsSA - Escola de Sargentos das Armas

EsSE - Escola de Saúde do Exército

ETAM - Escola Técnica do Arsenal de Marinha

FA - Força Armada

GTEME - Grupo de Trabalho para o Estudo da Modernização do Ensino

ICM - Instrução Cívico-Militar

ID - Iniciação Desportiva

IDEB - Índice de Desenvolvimento da Educação Básica

IME - Instituto Militar de Engenharia

Inf/CMRJ - Infantaria do Colégio Militar do Rio de Janeiro

LDBEN - Lei das Diretrizes e Bases da Educação Nacional

NAEB - Normas para Avaliação da Educação Básica

NAVAMAER - Olimpíada entre escolas das Forças Armadas 
NF - Nota Final

NP - Nota Periódica

NRRD - Normas Reguladoras do Regime Disciplinar dos Alunos dos Colégios Militares

OBMEP - Olimpíada Brasileira de Matemática das Escolas Públicas

OM - Organizações Militares

QCO - Quadro Complementar de Oficiais

R-128 - Regulamento de Uniformes do Exército

R-69 - Regulamento dos Colégios Militares

RD - Razões de Defesa

RICM - Regimento Interno dos Colégios Militares

RUE - Regulamento de Uniformes do Exército

SCMB - Sistema Colégio Militar do Brasil

SGEx - Secretaria Geral do Exército

Sgt - Sargento

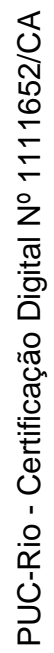

STE - Seção Técnica de Ensino 
Leopardos irrompem no templo e bebem até o fim os jarros de sacrificio; isso se repete sempre, sem interrupção; finalmente pode-se contar de antemão com esse ato e ele se torna em parte da cerimônia.

Franz Kafka, Aforismo XX

Em breve chegará o dia em que os atores irão acreditar que a sua máscara e os seus trajes são eles mesmos.

Epicteto, Discursos. Livro I, XXIX, 41

Sê corajoso, para que os homens ainda por nascer falem bem de ti.

Homero, Odisséia, Canto I, 295 